\title{
Pregnancy Depression during COVID-19 Pandemic
}

\author{
Pratiwi Puji Lestari $^{1}$, Zaiyidah Fathony ${ }^{1}$, Rizki Amalia ${ }^{1}$ \\ ${ }^{1}$ University of Muhammadiyah Banjarmasin, Indonesia \\ Corresponding Author: Pratiwi Puji Lestari
}

\begin{abstract}
The COVID-19 pandemic not only threatens people's health physically, but also mentally. $80 \%$ of mothers are predicted to experience symptoms of mood disorders in the first few days after giving birth. Symptoms of depression in pregnant women are similar to symptoms of depression that occur at other times in a woman's life cycle. The difference is due to the process of physiological changes during pregnancy and childbirth. This study was to determine the effect of the COVID-19 pandemic on the tendency of depression in pregnant women. The study is a quantitative observational study with a cross sectional design. The results show that there is a significant effect of the COVID-19 pandemic on the tendency to depression. The COVID-19 pandemic is a trigger factor for depression during pregnancy. Therefore, it is necessary to make efforts to prevent depression during pregnancy.
\end{abstract}

Keywords: COVID-19, pregnancy, depression

\section{INTRODUCTION}

The Covid-19 pandemic not only threatens people's health physically, but also mentally. Mental health is one of the impacts that threaten society during the Covid-19 pandemic. Mental health issues are increasingly being recognized as a significant and worrying secondary effect of the COVID-19 pandemic. Previous research on epidemics/pandemics suggests that families, especially mothers, may be at high risk, but this population has not been examined (Cameron et al., 2020)

More than $20 \%$ of pregnant and childbirth women in developing countries experience depression (Bitew et al., 2016). $80 \%$ of mothers are predicted to experience symptoms of mood disorders in the first few days after giving birth (Bloch et al., 2000). Symptoms of depression in pregnant women are similar to symptoms of depression that occur at other times in a woman's life cycle. The difference is due to the process of physiological changes during pregnancy and childbirth.

International studies emphasize that many cases of depression occur in women aged 18-44 years and during periods of fecundity such as pregnancy, childbirth, and the puerperium (Aktas \& Calik, 2015). Maternal depressive symptoms negatively affect the fetus during the prenatal period and affect the clinical aspects of labor, both directly and mediated by the quality of the prenatal attachment (Smorti et al., 2019). Physiologically, experiencing high levels of stress along with depression can activate inflammatory pathways involving maternal cortisol which can also lead to preterm birth (Mochache et al., 2018).

Many factors can cause high depression due to stress and anxiety such as sociodemographic factors that can influence depression during pregnancy. Emphasized in several studies that these factors, including age, low socioeconomic status, negative life experience, lack of a job with a satisfactory income, family problems, low educational status of pregnant women and their husbands add to the severity of depression symptoms (Aktas \& Calik, 2015).

This study was to determine the effect of the COVID-19 pandemic on the 
tendency of depression in pregnant women. In addition, this research is expected to improve the quality of midwifery services, especially comprehensive pregnancy, childbirth and postpartum care, including from the psychological aspect to improve the welfare of pregnant women.

\section{MATERIALS \& METHODS}

The study is a quantitative observational study with a cross sectional design. This design was to determine the extent of the influence of the Covid 19 pandemic on the tendency of depression in pregnant women.

The study population was all pregnant women who were affected by the
Covid 19 pandemic throughout the province of South Kalimantan. The number of research samples is pregnant women recorded in South Kalimantan Province. Sampling used purposive total sampling. Data collection is taken from primary data. The research instrument used a questionnaire filled out by the research subject.

The data collection tool used was the Center for Epidemiological Studies Depression Scale (CESD) as many as 20 question items and an observation sheet for data on socio-demographic characteristics that were all nauseated in an online form filled out.

\section{RESULT}

Table 1: The Effect of the Covid 19 Pandemic on the Mental Health of Pregnant Women
\begin{tabular}{|l|c|c|c|c|c|}
\hline \multicolumn{1}{|c|}{ Variabel } & Observed (N) & Expected (N) & Residual & Chi $^{2}$ & p-value \\
\hline CESD & & & & 13.067 & 0.000 \\
\hline No Depression & 44 & 30 & 14 & & \\
\hline Tend Depression & 16 & 30 & -14 & & \\
\hline Total & \multicolumn{6}{|c|}{6} & $\mathbf{6 0}$ & & & \\
\hline
\end{tabular}

The results show that there is a significant effect of the COVID-19 pandemic on the tendency to depression, assessed from the chi2 value which is higher than the df value and $p$-value $<0.05$. This shows that there are differences in the tendency of depression experienced by pregnant women during the COVID-19 pandemic.

\begin{tabular}{|c|c|c|c|c|c|c|c|c|c|c|c|}
\hline \multicolumn{2}{|c|}{ Variables } & \multicolumn{2}{|c|}{ No Depression } & \multicolumn{2}{|c|}{ Tend Depression } & \multicolumn{2}{|c|}{ Total } & \multirow[t]{2}{*}{ OR } & \multicolumn{2}{|c|}{ CI 95\% } & \multirow[t]{2}{*}{ p-value } \\
\hline & & $\mathbf{F}$ & $\%$ & $\mathbf{F}$ & $\%$ & $\mathbf{F}$ & $\%$ & & Min & Max & \\
\hline \multirow[t]{2}{*}{ Gestational age } & Trimester 2 & 18 & 40.9 & 9 & 56.3 & 27 & 45 & & & & \\
\hline & Trimester 3 & 17 & 38.6 & 4 & 25 & 21 & 35 & & & & \\
\hline \multirow[t]{2}{*}{ Parity } & Primigravida & 19 & 43.2 & 12 & 75 & 31 & 51.7 & 0.253 & 0.07 & 0.91 & 0.02 \\
\hline & Multigravida & 25 & 56.8 & 4 & 25 & 29 & 48.3 & & & & \\
\hline \multirow[t]{2}{*}{ Miscarriage History } & Never & 32 & 72.7 & 14 & 87.5 & 46 & 76.7 & 0.381 & 0.075 & 1.931 & 0.23 \\
\hline & Once & 12 & 27.3 & 2 & 12.5 & 14 & 23.3 & & & & \\
\hline Total & & 44 & 100 & 16 & 100 & 100 & 100 & & & & \\
\hline
\end{tabular}

The table shows the analysis of the influence of several characteristic variables on the tendency of depression in pregnant women. Among these variables, parity is the only variable that has a statistically significant value. $\mathrm{p}$ value of the parity variable is $0.02(p<0.05)$. This shows that parity has an influence on the tendency of depression in pregnant women.

\section{DISCUSSION}

Anxiety, depression, and stress during pregnancy are serious health problems that occur in society. Although there are no recorded deaths from COVID19 in pregnant women, the results of this study are still preliminary (pilot study) and still require confirmation and further research. It is hoped that the findings of this study can reveal the effect on mental wellbeing among pregnant women in South Kalimantan.

Depression during pregnancy and the perinatal period may be difficult to identify, even though more than a quarter of respondents have a tendency to depression. From the results of the analysis of influence, the COVID-19 pandemic has a tendency to 
have a significant influence on depression in pregnant women, this can be seen from the statistical values that show differences in the mental health state of pregnant women (depression) during the COVID-19 pandemic.

The effects of the COVID19 pandemic show a psychological impact on the mental health of pregnant women, including depression (Saccone et al., 2020). The results of this study indicate that there is a significant effect of the COVID-19 pandemic on the depression variable with a $\mathrm{p}$ value $(0.000)$. The data shows that there are differences in the mental health state (depression) of pregnant women during the COVID-19 pandemic and not during the COVID-19 pandemic.

Similar studies aimed at investigating the effects of the COVID-19 pandemic on depression and anxiety in pregnant women showed statistically significant results (Durankuş \& Aksu, 2020; Yildiz et al., 2017). There is an urgent need to provide psychosocial support to this population during times of crisis. Otherwise, side effects may occur during pregnancy and thus affect the mother and fetus (Durankuş \& Aksu, 2020)

In this study, variables other than the COVID-19 pandemic were investigated. Other variables studied were parity and history of miscarriage. Based on the results, multigravida pregnant women have a tendency to depression as much as 0.25 times greater than pregnant women who are primigravida. the tendency of depression in multigravida is lower than in primigravida. Parity has a significant on the tendency to depression. The same thing is also explained in a systematic study about maternal depression tendencies, parity is one of the causes of depression tendencies. Primigravida tend to be more at risk for depression due to lack of maternal experience and lack of information (SomaPillay et al., 2016)

This is different from the results of studies related to the effect of characteristics of pregnant women on the tendency of depression which showed statistically significant results for factors of age, education and gestational age (van de Loo et al., 2018)

The direct impact of depression during pregnancy has been associated with various complications that can occur during pregnancy, childbirth and the puerperium, such as premature birth (Becker et al., 2016b). low birth weight, fetal growth restriction (Field, 2017). It is also associated with hypertension, preeclampsia, and gestational diabetes (Alder et al., 2007; Becker et al., 2016b)Early postpartum depression is a predisposing factor for delayed lactation (Lestari et al., 2020)

Insignificant results from some of the variables studied are possible due to research bias. Some of the causes of bias in this study include the limited number of samples of pregnant women who fill out questionnaires, the use or collection of online questionnaires is also an obstacle because it cannot reach pregnant women widely related to connections or in some areas many pregnant women do not have access to smart devices so that The sample cannot represent all pregnant women in South Kalimantan.

\section{CONCLUSION}

The COVID-19 pandemic is a trigger factor for depression during pregnancy. Prevention efforts need to be done to anticipate depression during pregnancy. Providing information and education counseling and routinely conducting psychological health screening of pregnant women is a real effort that can be done by health workers, especially midwives. For further research, wider data on pregnant women and more samples are needed to reduce bias in the results.

Acknowledgement: None

Conflict of Interest: None

Source of Funding: None 


\section{REFERENCES}

1. Aktas, S., \& Calik, K. Y. (2015). Factors affecting depression during pregnancy and the correlation between social support and pregnancy depression. Iranian Red Crescent Medical Journal, 17(9).

2. Alder, J., Fink, N., Bitzer, J., Hösli, I., \& Holzgreve, W. (2007). Depression and anxiety during pregnancy: a risk factor for obstetric, fetal and neonatal outcome? A critical review of the literature. The Journal of Maternal-Fetal \& Neonatal Medicine, 20(3), 189-209.

3. Becker, M., Weinberger, T., Chandy, A., \& Schmukler, S. (2016a). Depression during pregnancy and postpartum. Current Psychiatry Reports, 18(3), 32.

4. Becker, M., Weinberger, T., Chandy, A., \& Schmukler, S. (2016b). Depression During Pregnancy and Postpartum. https://doi.org/10.1007/s11920-016-0664-7

5. Bitew, T., Hanlon, C., Kebede, E., Medhin, G., \& Fekadu, A. (2016). Antenatal depressive symptoms and maternal health care utilisation: a population-based study of pregnant women in Ethiopia. BMC Pregnancy and Childbirth, 16(1), 301. https://doi.org/10.1186/s12884-016-1099-1

6. Bloch, M., Schmidt, P. J., Danaceau, M., Murphy, J., Nieman, L., \& Rubinow, D. R. (2000). Effects of Gonadal Steroids in Women With a History of Postpartum Depression -- Bloch et al_ 157 (6) 924 -Am J Psychiatry. June, 924-930. https://doi.org/10.1176/appi.ajp.157.6.924

7. Cameron, E. E., Joyce, K. M., Delaquis, C. P., Reynolds, K., Protudjer, J. L. P., \& Roos, L. E. (2020). Maternal psychological distress \& mental health service use during the COVID-19 pandemic. Journal of Affective Disorders, 276, 765-774. https://doi.org/10.1016/j.jad.2020.07.081

8. Durankuş, F., \& Aksu, E. (2020). Effects of the COVID-19 pandemic on anxiety and depressive symptoms in pregnant women: a preliminary study. The Journal of MaternalFetal \& Neonatal Medicine, 1-7. https://doi.org/10.1080/14767058.2020.176 3946

9. Field, T. (2017). Prenatal anxiety effects: A review. Infant Behavior and Development, 49 ,

120-128. https://doi.org/https://doi.org/10.1016/j.infb eh.2017.08.008

10. Lestari, P. P., Nurdiati, D. S., \& Astuti, D. A. (2020). Effects of Postpartum Depression Symptoms On the Success of Breastfeeding In Hospital of Bantul. Healthy-Mu Journal, 3(2), 46-51.

11. Mochache, K., Mathai, M., Gachuno, O., Vander Stoep, A., \& Kumar, M. (2018). Depression during pregnancy and preterm delivery: a prospective cohort study among women attending antenatal clinic at Pumwani Maternity Hospital. Annals of General Psychiatry, 17(1), 1-8.

12. Saccone, G., Florio, A., Aiello, F., Venturella, R., De Angelis, M. C., Locci, M., Bifulco, G., Zullo, F., \& Sardo, A. D. S. (2020). Psychological impact of coronavirus disease 2019 in pregnant women. American Journal of Obstetrics \& Gynecology, 223(2), 293-295.

13. Smorti, M., Ponti, L., \& Tani, F. (2019). Maternal depressive symptomatology during pregnancy is a risk factor affecting newborn's health: A longitudinal study. Journal of Reproductive and Infant Psychology, 37(4), 444-452.

14. Soma-Pillay, P., Catherine, N.-P., Tolppanen, H., Mebazaa, A., Tolppanen, H., \& Mebazaa, A. (2016). Physiological changes in pregnancy. Cardiovascular Journal of Africa, 27(2), 89.

15. van de Loo, K. F. E., Vlenterie, R., Nikkels, S. J., Merkus, P. J. F. M., Roukema, J., Verhaak, C. M., Roeleveld, N., \& van Gelder, M. M. H. J. (2018). Depression and anxiety during pregnancy: The influence of maternal characteristics. Birth, 45(4), 478489.

16. Yildiz, P. D., Ayers, S., \& Phillips, L. (2017). The prevalence of posttraumatic stress disorder in pregnancy and after birth: A systematic review and meta-analysis. Journal of Affective Disorders, 208, 634645.

https://doi.org/https://doi.org/10.1016/j.jad.2 016.10.009

How to cite this article: Lestari PP, Fathony Z, Amalia R. Pregnancy depression during COVID19 pandemic. International Journal of Science \& Healthcare Research. 2021; 6(4): 7-10. DOI: https://doi.org/10.52403/ijshr.20211002 